\title{
A New Value for Johnson Cook Damage Limit Criterion in Machining with Large Negative Rake Angle as Basis for Understanding of Grinding
}

\author{
Mansur Akbari ${ }^{1}$, Sebastian Buhl ${ }^{2,3}$, Christian Leinenbach ${ }^{3}$, Konrad Wegener ${ }^{1}$ \\ ${ }^{1}$ Institute of Machine Tools and Manufacturing, ETH Zurich, Leonhardstrasse 21, 8092 Zurich, Switzerland \\ akbari@alumni.ethz.ch, http://www.iwf.mavt.ethz.ch \\ ${ }^{2}$ ABB Switzerland Ltd., Semiconductors, BiMOS, \\ PTS3-2, Fabrikstrasse 3, 5600 Lenzburg, Aargau, Switzerland \\ ${ }^{3}$ Empa-Swiss Federal Laboratories for Materials Science and Technology, Ueberlandstrasse 129, \\ 8600 Duebendorf, Switzerland
}

Key words: Johnson-Cook Damage; Implicit FEA; Micromachining; Three Dimensional Chip Formation; Negative Rake Angle; Ti-6Al-4V Grinding

\begin{abstract}
.
Grinding is one of the most complex manufacturing processes in industry and understanding its physics is still fairly limited due to the stochastic nature of the process. The physics behind the grinding process can be better understood through thermomechanical analysis of grain-material interactions, enabling the optimization of the process and grinding tool. When simulating the chip formation in machining processes, difficulties arise when the negative rake angle is large, when thermal effects on the tool and workpiece become prominent and when there is the necessity to consider damage within the constitutive equations of the workpiece material. These difficulties become further intensified given small depths of cut as in the case of grinding and the need for three-dimensional models.

A coupled thermomechanical dynamic analysis is performed to simulate linear machining experiments effectuated by single diamond grains. Damage is described within a JohnsonCook model. The damage parameters when machining Ti-6Al-4V are optimized in a three dimensional model and a new concept of applying a damage limit when machining with negative rake angle is suggested. Here, a Fortran subroutine is written to calculate the damage field variable. The simulated cutting forces and temperature in the tool as well as the workpiece are validated. Validation experiments are carried out by single grain machining experiments at a depth of cut of $30 \mu \mathrm{m}$ and at a linear cutting velocity of $0.8 \mathrm{~m} / \mathrm{s}$. Numerical challenges, such as chip separation criterion and settings of adaptive remeshing are addressed. Finally, it is shown that with an increase in the cutting edge radius, cutting forces and especially passive forces increase.
\end{abstract}

\section{Introduction}

Grinding is defined as the machining with geometrically undefined cutting edges and mainly applied to precision machining (DIN, 2003) and finishing. It can achieve high dimensional and geometrical accuracy as well as high material removal rates while also being able to machine hard-to-cut and ultra-hard materials. Diamond grains are distinguished because of its low coefficient of friction, high thermal conductivity and high wear resistivity resulting in prolonged tool lifetimes. Diamond is also used to machine hard-to-cut materials. For instance, researchers like (Minton et al., 2013) have proved the importance of using diamond coated tools when turning titanium, in which temperatures reach in upwards of $500^{\circ} \mathrm{C}$ given a cutting velocity of $80 \mathrm{~m} / \mathrm{min}, 1 \mathrm{~mm}$ depth of cut, feed rate of $0.2 \mathrm{~mm} / \mathrm{rev}$ and without the use of coolant. The abrasive grains in grinding tools are held within either a monolayer or a consumable layer and normally exhibit a negative rake angle. Understanding 
the physics of the grinding process is difficult because of its stochastic nature, high cutting speed, high temperature gradients and depth of cuts in the order of micrometers. High performance grinding as well as long service life of the grinding tool can be accomplished by studying the grinding characteristics such as grain-material interaction and grinding forces. To lay the basis for the stochastic description of the grinding tool and to reduce the complexity of the physics of the process, one can set sights on a single grain. For example, (Akbari et al., 2012) analyzed the residual stresses of diamonds induced after brazing for monolayer grinding tools. In the present paper, the interaction between single grains with a workpiece material is studied.

Owing to its excellent mechanical properties especially at elevated temperatures, high temperature alloys are often difficult to machine and optimal processing parameters have yet to be defined. Thermal residual stresses due to temperature gradients between the machined surface and bulk material arise during the grinding process. When the plastically deformed surface layer cools, (Cotell et al., 1994) explained that the shrinkage of the surface is hindered by the bulk material generating tensile residual stresses. Reducing the thermal residual stress in the processed subsurface, which adds to the mechanical residual stress, is of great concern in industrial applications. The high temperature that is generated due to frictional heating and plastic deformation during grinding is the primary source of defects on the processed surface. As mentioned by (Brinksmeier et al., 1982; Jackson and Hitchiner, 2013), transient temperature gradients contributes to residual stresses and micro cracking on ground surfaces. (Sauvage et al., 2003; Skorupski et al., 2013) also showed that the localized temperature in the case of thin workpiece features can cause warping or even induce material phase transformations.

Excessive heat accumulation at the boundary between the grain and workpiece accelerates the wear of cutting edges and consequently leads to inefficient machining. This in turn leads to further input of heat to the grinding zone and causes greater damage to the tool and workpiece. Moreover, high temperatures increase the risk of grain pullout due to fracture, wear or chipping. Thus, by controlling the cutting temperature, the service life of the tool and productivity increases. Through the thermal analysis of the machining processes, the source of heat flux plays a key role. Most authors considered a uniform heat flux (Chang, 2007; Liu et al., 2009; Liu and Chou, 2007; Umbrello et al., 2007), while a select few considered a nonuniform heat flux in the rake face, e.g. (Haddag et al., 2013), to calculate the temperature distribution. Unlike previous numerical studies, the present model calculates the heat flux in a coupled thermomechanical analysis by considering both frictional heat and heat generated due to workpiece surface deformation. Since frictional heat is considered, flash temperature can also be studied. As mentioned in (Blau, 1992; Blok, 1963), the flash temperature is localized at areas of contact where frictional heat dissipation occurs. The duration of the flash temperature is often in the order of microseconds, which is typically the interaction time of each single grain during the grinding process. Experimentally detecting the flash temperature is difficult. Furthermore, numerical modelling of the flash temperature, owing to extreme gradients and the unknown heat flux coupled between the workpiece and the grain, is not easy.

Finite element analysis (FEA) allows for a better understanding of grain-material interactions during single grain test. Subsequently, bond failure can be predicted and the causes thereof can be revealed. Also, the vectors of critical forces at the contact zone can be determined so that the orientation and shape of the grains can be optimized and accordingly, the grinding tool can then be appropriately engineered. In the following, common methods used to analyze machining processes are mentioned. As reported in (Schermann et al., 2006), when using extensive mass scaling and an explicit time integration scheme to reduce the 
computation time, unrealistic cutting forces were calculated. Thermal modelling of surface grinding was carried out by (Mamalis et al., 2003) using implicit time integration. Furthermore, implicit time integration was also used by (Lohkamp et al., 2012) for micromachining of titanium with the consideration of crystal plasticity. According to (Aurich et al., 2009), the simulation of burr formation can also be carried out by the implicit time integration scheme. In the present study, to simulate grain-material interactions in single grain machining experiments, the implicit time integration scheme is selected. This is to ensure a stable solution during chip formation and to avoid unrealistic results.

The kinematics of chip formation and deformation in the grinding process can be explained by Lagrangian, Eulerian, Arbitrary Lagrangian-Eulerian (ALE) adaptive meshing and a Coupled Eulerian-Lagrangian (CEL) formulation. The ALE is a general formulation in which the FE mesh is neither attached to the material nor fixed in the space. Instead, as (Movahhedy et al., 2002) have shown, it may have an independent and arbitrary motion which can be prescribed by the analyst. Therefore, ALE can model the large deformations by allowing the mesh to move independently of the material. Since ALE does not alter the topology of the elements and their connectivity, it implies some limitations of this method to maintain a highquality mesh under severe deformation scenarios. (Movahhedy et al., 2000) used ALE to simulate the machining of steel and was mainly used to study local effects at the cutting zone. It was shown that ALE has problems with 3D simulations and complex models. Another approach to prescribe mesh separation is to define a damage layer between the chip and workpiece. Then during the machining process, the damage layer or in other words the sacrificial layer with help of element deletion is removed and the chip and the workpiece separate from one another. For instance (Hokka et al., 2012) simulated in 2D, serrated chip formation when machining a titanium alloy with this technique. This method, however, is unable to model the spring back of the workpiece after machining. Furthermore, since defining the exact location of the damage layer in 3D models and especially in single grain machining simulations is difficult, this approach is not implemented in the present study. Another appropriate method which is used in the present study is using remeshing; an early basic algorithm of which is explained in (Tezuka, 1992) and in more detail in section 3.2. With help of a similar adaptive remeshing algorithm, and by implementing a user-defined subroutine, coupled thermomechanical chip formation in 2D is possible and has been demonstrated successfully using explicit time integration in (Issa et al., 2011).

To validate the simulation results, some state variables or quantities that are important in the machining process are compared. In the following, reasons for selecting those state variables are discussed. In machining processes, large negative rake angles typically lead to higher cutting forces. As shown by (Aurich et al., 2010), machining with large negative rake angles induces high compressive loads and subsequently generates high temperatures. In addition, (Karpuschewski and Binh, 2007) showed that, with larger chip thickness at constant cutting velocities higher cutting forces occur while for constant chip thickness the higher velocities reduces the cutting forces. Therefore, the state variables that are validated in the present study are cutting forces, normal force, passive force and temperature. Discontinuous chips which typical characterize a grinding process can be easily removed from the grainsurface interaction zone. This helps reduce tool wear and improves process performance by carrying heat away from the interaction zone. Therefore, it is important to understand the morphology of the chips and the ground surface during the grinding process. As proved by (Karpuschewski et al., 2013; Wyen and Wegener, 2010), the cutting edge radius greatly influences cutting forces. Therefore, in the present study, the influence of cutting edge radius on cutting forces is also investigated. In the present paper, a dynamic coupled 
thermomechanical finite element method with an implicit time integration scheme and updated Lagrangian description is used. It is intended to simulate 3D micromachining given large negative rake angles in 3D while considering a user-defined damage constitutive law at the workpiece.

\section{Experimental setup}

General purpose grinding tools have many abrasive grains which are distributed stochastically. In monolayer grinding tools, to improve the topography of the ground workpiece and optimize the grinding process, so called engineered grinding tools (EGTs) can be used which exhibit a defined grain pattern. Studying the interaction of single grains with the workpiece helps to understand the grinding process and the grinding tool design of EGTs. Some of these evaluations can be found in (Anderson et al., 2011; Brinksmeler and Glwerzew, 2003; Li and Rong, 2011; Matsuo et al., 1989). These experimental studies are referred to as single grain scratch tests and are intended to understand grain-matter interactions, which is also the goal of this study.

Cutting speed in grinding is typically around 30 times faster than in other machining operations which complicate the analysis. The machining tests are limited in speed due to limitations of the used machine tool, due to the lowest eigenfrequency of the force measuring setup as well as due to the maximum frame rate of infrared thermo-camera. For these reasons, the linear cutting speed is set to $0.8 \mathrm{~m} / \mathrm{s}$.

Depending on the grinding characteristics, three mechanisms can be distinguished during grain-material interaction: rubbing, ploughing and cutting. Rubbing and ploughing mainly lead to pile-ups along the furrow of the single grain. Ideally, grinding should lead to cutting and removal of material rather than displacement. Although rubbing and ploughing in high performance grinding should be minimized. Ploughing helps subsequent grains to cut and remove the plastically deformed material by low cycle fatigue. According to (Hou and Komanduri, 2003), in conventional grinding tools only a very small fraction of the grains, passing over the workpiece per second merely rub and plough into the material. It can also happen that the three mechanisms of rubbing, ploughing and cutting take place at the same grain and in one rotation of the grinding tool. As mentioned in (Hou and Komanduri, 2003), the grains that participate in rubbing and ploughing in grinding account for $\sim 18 \%$ during surface grinding and stock removal grinding (SRG), and $\sim 3.8 \%$ during form and finish grinding (FFG). An even smaller fraction of the grains, $\sim 1.8 \%$ for SRG and $\sim 0.14 \%$ for FFG participate in actual cutting. Thus, in high performance grinding it is important to find a solution so that the grains, which are in contact with the workpiece, mainly do the cutting. Thus, in the present study to simulate the chip formation mechanism and validate it with experiment, $30 \mu \mathrm{m}$ depth of cut for the linear movement of the tool with large negative rake angle is considered.

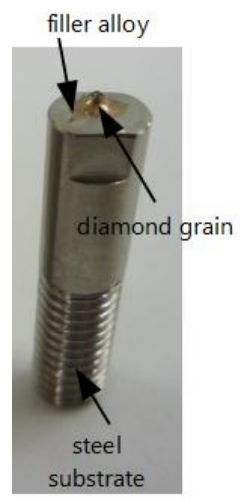

Fig. 1: Position of the brazed parts. 
The single grain tool is composed of a diamond brazed on a steel pin, as shown in Fig. 1. Truncated-octahedron single crystalline synthetic diamonds (SDB ${ }^{\mathrm{TM}} 1125$ 2025, Element Six e6 ${ }^{\mathrm{TM}}$, ServSix $\mathrm{GmbH}$, Karlstein, Germany) are used. This tool is later threaded into a tool holder and clamped into a machine tool. The pin material is austenitic stainless steel $\mathrm{X} 2 \mathrm{CrNiMo18-14-3}$. This material is used in grinding tool bodies and is suitable for the applied high brazing temperatures since it does not experience any phase transformations. The dimensions of the pin are a diameter of $6.0 \mathrm{~mm}$, a height of $25.0 \mathrm{~mm}$ and a M6 thread of 12.0 $\mathrm{mm}$ in length for fixation.

\subsection{Determination of diamond grain shape}

Polyhedral diamond grains of size D851, i.e. $710-850 \mu \mathrm{m}$, are selected for this study. In the case of selecting smaller diamonds, fewer details concerning the temperature field can be detected during the machining process; therefore, smaller diamonds are not used. Diamond grains which are undamaged and show homogeneity, are chosen. Then diamond grains, and the steel pins are immersed in ethanol based solution and cleaned in ultrasonic cleaning system. To stick the diamond grains to the SEM pin stub mounts, double coated carbon conductive tabs and Conductive Liquid Silver Paint (G302, 25-50\% Methyl isobutyl ketone and $50-75 \%$ Silver, PLANO GmbH, Wetzlar, Germany) are used. After flooding Argon gas in the chamber, approximate $10 \mathrm{~nm}$ gold is coated on diamonds by Balzers Sputter Coater SCD 050 in $40 \mathrm{~mA}, 410 \mathrm{~V}, 0.05 \mathrm{mbar}$ vacuum chamber and for sputter time of $70 \mathrm{~s}$. Another setup of the coating with carbon is also applied on uncoated diamonds with Baltec BAE 120, in $3.5 \times 10^{-5}$ mbar, $\sim 1800 \mathrm{~V}, \sim 70 \mathrm{~mA}$, sputter rate of $\sim 0.1-0.13 \mathrm{~nm} / \mathrm{s}$ and both high vacuum and emissions are adjusted such that the sputter rate became stable and within the desired range. Then the prepared samples are imaged by SEM (FEI Quanta ${ }^{\mathrm{TM}} 200$ FEG). For example, Fig. 2a shows the SEM image of a cubo-octahedral diamond.
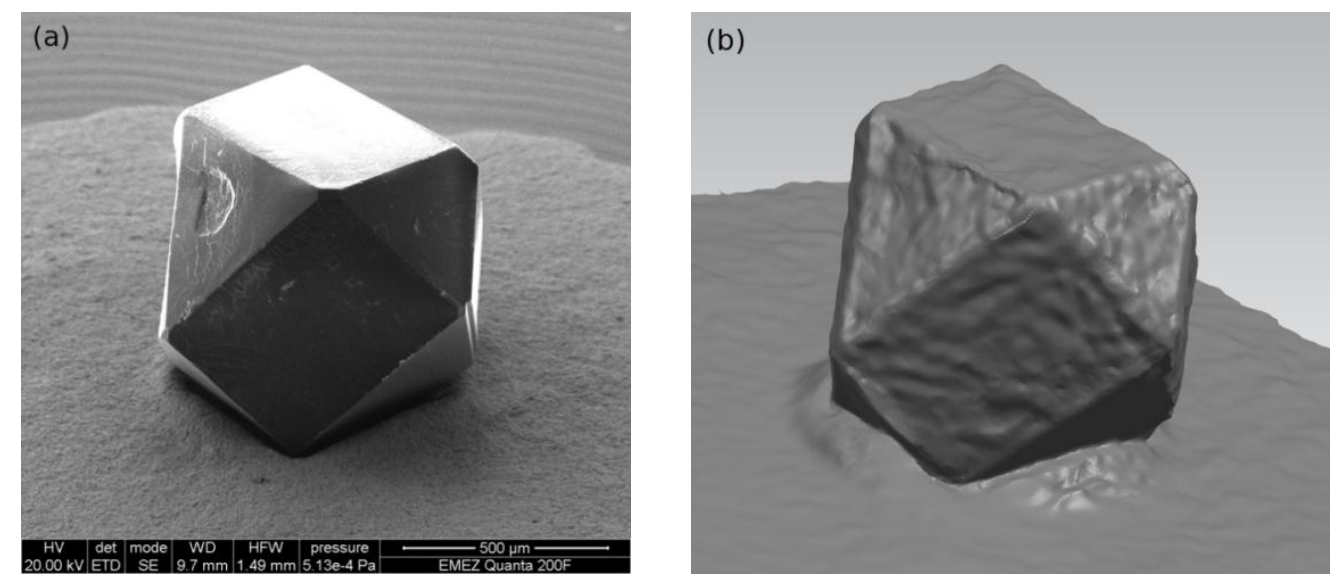

Fig. 2: Cubo-octahedral diamond: (a) SEM image. (b) 3D model of the diamond after measurement with focus variation light microscope of Alicona ${ }^{\circledR}$ and post processing with Geomagic Studio ${ }^{\circledR}$.

Then the coated diamonds are imaged by 3D light microscope Alicona-InfiniteFocus ${ }^{\mathrm{TM}}$ (Alicona Imaging $\mathrm{GmbH}$, Grambach/Graz, Austria). With the help of a rotational unit, the complete 3D diamond grain shape is recorded, allowing an accurate modeling. In addition, the results of the Alicona light microscope is compared with the SEM images. Then the 3D images from the Alicona microscope are modified by Geomagic Studio ${ }^{\circledR}$ to remove the measuring noise and modify the surface to adapt to the SEM image. The diamond surface quality in Fig. 2b shows that the modified model by Geomagic Studio ${ }^{\circledR}$ is still not suitable for FEM model. Thus, the outputs of Geomagic Studio ${ }^{\circledR}$ are imported to NX Unigraphics ${ }^{\circledR}$ to 
draw and fit planar faces on the faces of the imported diamond from Geomagic Studio ${ }^{\circledR}$. This procedure is necessary to overcome the problems of meshing the diamond. Then based on (Akbari et al., 2016) cutting edge radius of $7 \mu \mathrm{m}$ is considered for the diamonds.

\subsection{Brazing procedure}

Prior to brazing, the steel substrates are cleaned from surface contaminations using acetone in an ultrasonic bath. A degassing step is carried out under high-vacuum $\left(10^{-5}-10^{-6} \mathrm{mbar}\right)$ in a Torvac high-vacuum furnace (Cambridge Vacuum Engineering LTD, Cambridge, United Kingdom) for $45 \mathrm{~min}$ at $800^{\circ} \mathrm{C}$ in order to remove organic residues in the superficial layers of the substrate due to the machining process. Afterwards, the steel pin, exhibiting a small amount of adhesive on its top surface, is positioned so as to make contact with the grain. Then the adhesive is allowed to cure at $150^{\circ} \mathrm{C}$ for roughly $30 \mathrm{~min}$. $\mathrm{An} \mathrm{Ag}$-Cu-based active filler alloy of Cusil-ABA ${ }^{\mathrm{TM}}$ (Wesgo Metals, Hayward, CA, USA) is used exhibiting a granularity of -325 mesh size. According to (Buhl, 2012), the filler alloy has a solidus and liquidus temperature of $\mathrm{T}_{\mathrm{s}}=780^{\circ} \mathrm{C}$ and $\mathrm{T}_{1}=815^{\circ} \mathrm{C}$ respectively. The filler alloy powder is mixed with a binder and applied as paste. It is directly distributed around the diamond grain, and afterwards the whole sample is dried at $150^{\circ} \mathrm{C}$. On top of each steel pin one polyhedral diamond grain of size D851is brazed. The brazing process is carried out in the aforementioned high-vacuum furnace at $850^{\circ} \mathrm{C}$ for $10 \mathrm{~min}$.

\subsection{Machining test and force measurement}

The single grain machining experiments are carried out according to the following grain engagement orientation depicted in Fig. 3. The flow of workpiece is indicated, i.e. the diamond plunges with the (111)-facet into the workpiece material. This implies that the rake face is a (111) surface. Prior to the brazing and single grain machining tests, the single grain is orientated under the 3D light microscope to precisely define zero clearance angles.

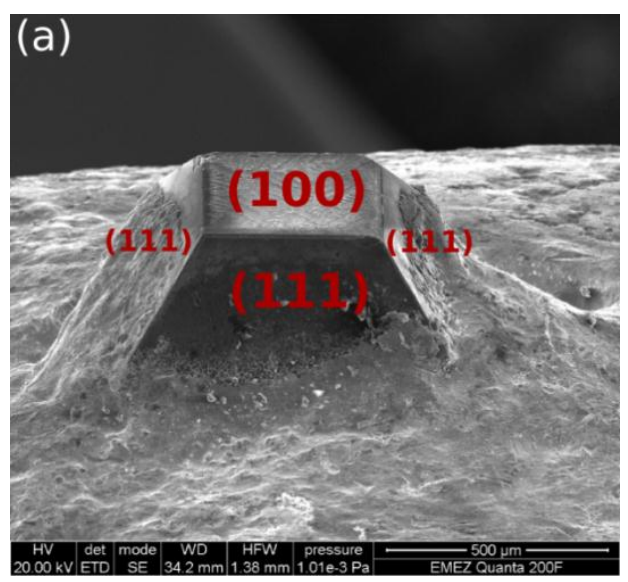

(b)

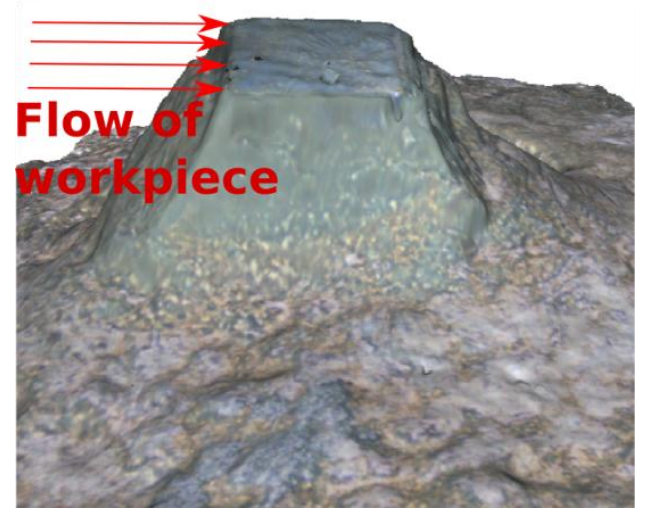

Fig. 3: Grain engagement orientation; (a): SEM micrograph of rake-face identified with (111) Miller index, (b): 3D optical microscope image of the engagement edge indicated by arrows. The picture is made by AliconaInfiniteFocus ${ }^{\mathrm{TM}} \mathrm{G} 4$ and with $5 \mathrm{x}$ magnification lens.

To verify that the clearance angle after brazing is within a tolerance of $\pm 0.5^{\circ}$, the brazed tools are again measured. Then as shown in Fig. 4, by digital handheld microscope of DinoLite Premier AM7013MZT (AnMo Electronics Corporation, Taiwan) the brazed diamond tool is properly rotated in the machining-center to adjust for the engagement orientation. Engagement is oriented so that the longest undamaged diamond edge makes contact with the workpiece, and is perpendicular to the cutting speed $V_{c}$. 
The workpiece has the dimensions of $80 \times 40 \times 8 \mathrm{~mm}^{3}$, while the base material is Ti-6Al-4V (Grade 5 titanium sheet, hot formed annealed, ASTM B 265). Micromachining of Ti-6Al-4V plays a leading role in industries such as medical and aerospace due to its high strength-toweight ratio, excellent corrosion resistance and biocompatibility. To reduce the uncertainty of the depth of cut, two sides of the Ti-6Al-4V workpieces are lapped by Stähli lapping machine (Stähli Läpp Technik, Biel, Switzerland) with SiC and oil. This ensures parallelism with an uncertainty of approximately $5 \mu \mathrm{m}$. The face of the workpiece, where the machining is expected to take place is further polished with diamond abrasive grains and oil followed by chemical polishing liquid of AWS-PMC $2110.0^{\mathrm{TM}}$. Then the workpiece is mounted on a calibrated multi-component dynamometer, Kistler MiniDyn type Z21317AS-v1 (Kistler Instrument AG, Winterthur, Switzerland), in order to record the force signals. The frequencies of the workpiece-sensor system mounted on rigid base related to the lowest eigenmodes in frequency response function (FRF) between the excitation in one direction and the three measuring directions, are $4,4.8$ and $4.6 \mathrm{kHz}$ for $\mathrm{F}_{\mathrm{x}}, \mathrm{F}_{\mathrm{y}}$ and $\mathrm{F}_{\mathrm{z}}$ respectively. In addition, the transfer function of the force sensor shows that there is insignificant magnification until the frequency response function reaches $2 \mathrm{kHz}$. Thus, a low pass filter of $2 \mathrm{kHz}$ is used for the force sensor.

An ultra-precise 3-axis machining-center of PRÄZOPLAN, developed and built by IWFETH Zurich, which is based on aero-statically planar guide with position uncertainty of \pm 1 $\mu \mathrm{m}$ and repetitive accuracy of $\pm 0.4 \mu \mathrm{m}$ is used to perform the experiments. The brazed pin is fixed into the tool holder. The spindle itself is also clamped to avoid undesired rotation, ensuring that the grain's engagement orientation remains unchanged. The experimental setup is shown in Fig. 4.

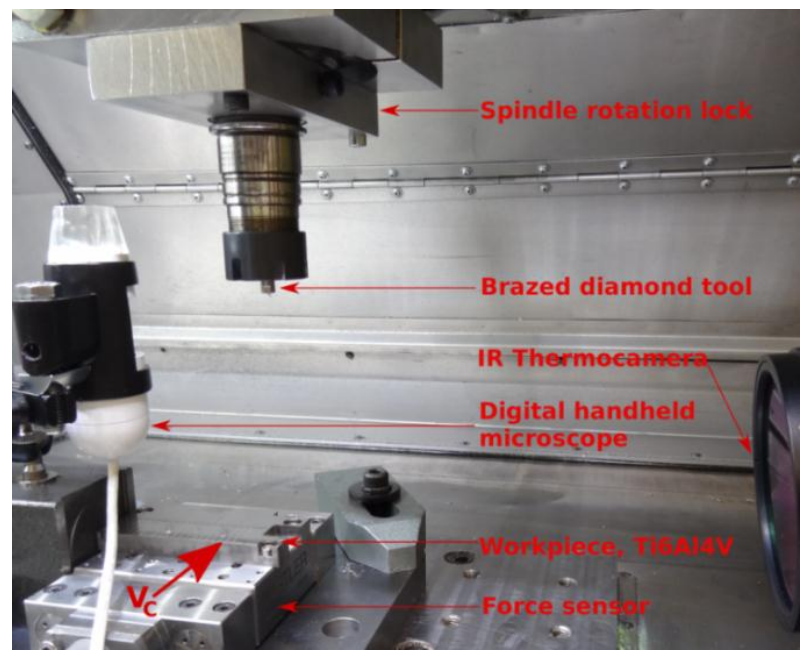

Fig. 4: Experimental setup of single diamond machining test. Direction of cutting velocity is shown by $\mathrm{V}_{\mathrm{C}}$.

Uncertainty of the experimental values stems from several parameters, namely the accuracy of the machine tool, geometric tolerance and parallelization of the two sides of the workpiece, exact orientation of the diamond in the tool holder, measurement errors, influence of the environment and influence of the operator. The procedure of calculating the uncertainty can be found in (Akbari et al., 2016).

The spindle moves in a linear direction across the workpiece with constant cutting speed of $0.8 \mathrm{~m} / \mathrm{s}$ and $30 \mu \mathrm{m}$ depth of cut. Each of the experiments is repeated more than three times to assure the repeatability of the experimental results. Additionally, before each experiment, the diamond is monitored to ensure wear on its cutting edges and planes is absent. 


\subsection{Thermography}

During metal machining, measurement of the temperature field is essential to validate numerical results. Typically, numerical results are compared with reality by measuring parameters such as forces on the tool. With additional temperature measurements from an infrared camera, a full set of variables are made available providing a comprehensive verification of simulated results. The information gained from the temperature field is informative since temperature is a direct result of local plastic deformation and directly influences the behavior of the material. On the other hand, the temperature field can also be exploited for inverse solution problems. As the material undergoes extreme processes, material properties under these conditions are not available. With field information of the process, the material parameters can be extracted directly from the machining process by minimizing the difference between a computed and an experimental temperature field.

There are several methods to monitor temperature during machining. They can be classified according to resistive methods, thermocouples, thermophysical processes and spectral radiation thermometry. These methods are explained in (Childs, 2001; Davies et al., 2007). Infrared radiation (IR) thermography is a non-contact measurement method, which is especialy advantageous during machining. The detector of the IR camera is a focal plane array (FPA) made of thermal or quantum detectors. Thermal detectors cover a broader IR spectrum, however, are less sensitive and slower compared to quantum detectors. Thus, the present study uses an IR camera with quantum detector. Spectral radiation thermometry with infrared thermo-camera of FLIR ${ }^{\circledR}$ X6580sc (Detector:InSb, General frame rate: $1100 \mathrm{~Hz}$ at $160 \times 128$ pixels, Max frame rate: $4200 \mathrm{~Hz}$ at $640 \times 8$ pixels, lens diameter: $120 \mathrm{~mm}, \mathrm{FOV} \approx 9.6 \times 7.68 \mathrm{~mm}$, Aperture F/3, Pixel pitch: $15 \mu \mathrm{m}$ ) is used. Since emissivity is a function of wavelength, surface roughness, direction and temperature, black dot stickers with known emissivity are used during measurements. This ensures that the correct output can be displayed during post processing

\section{Numerical methodology}

\subsection{Coupled-thermomechanical finite element analysis}

Three-dimensional simulations of the grinding process, interaction of several grains and their influence on surface roughness, temperature gradient and the distribution of the full residual stress tensor in the ground material can all be analyzed in a 3D model. Large temperature changes within the workpiece and high temperatures in the tool are expected during machining. The change of temperature, changes the material properties, which should be taken into account in mechanical analysis. However, the temperature field depends on the dissipated energy, which is a result of the mechanical analysis. The change in the temperature distribution contributes to the deformation of the workpiece through thermal strains and through changes in the temperature dependent material properties. In addition, heat conducted between the surface of the grain and the surface of the chip as well as the ground workpiece depends strongly on the separation of the surfaces and the pressure transmitted across the surfaces. Furthermore, the generated heat causes a rise in the workpiece temperature and may cause thermal damage in the workpiece. The generated heat might also cause thermal softening of the filler alloy and increases the risk of grain pull out. Therefore, thermomechanical coupling needs to be taken into account in the simulation of all machining processes, especially grinding.

The fully coupled thermomechanical analysis that is performed in this study is based on the equilibrium and energy balance equation using a staggered algorithm approach. This means that each increment consists of two field equations which are solved in sequence. As it is 
depicted in Fig. 5 from (MSC Software, 2013), firstly the heat transfer problem is solved for the current configuration based on the current boundary conditions. This step includes changing areas of surfaces subjected to a surface flux, thermal contact conditions and heat production due to dissipation of plastic work in order to calculate the thermal operator. Secondly, the mechanical problem is solved for the current temperature distribution. This second step includes the thermal strains and material property changes due to temperature. At the end of each step, the current configuration is updated to serve as a new reference configuration for the next step.

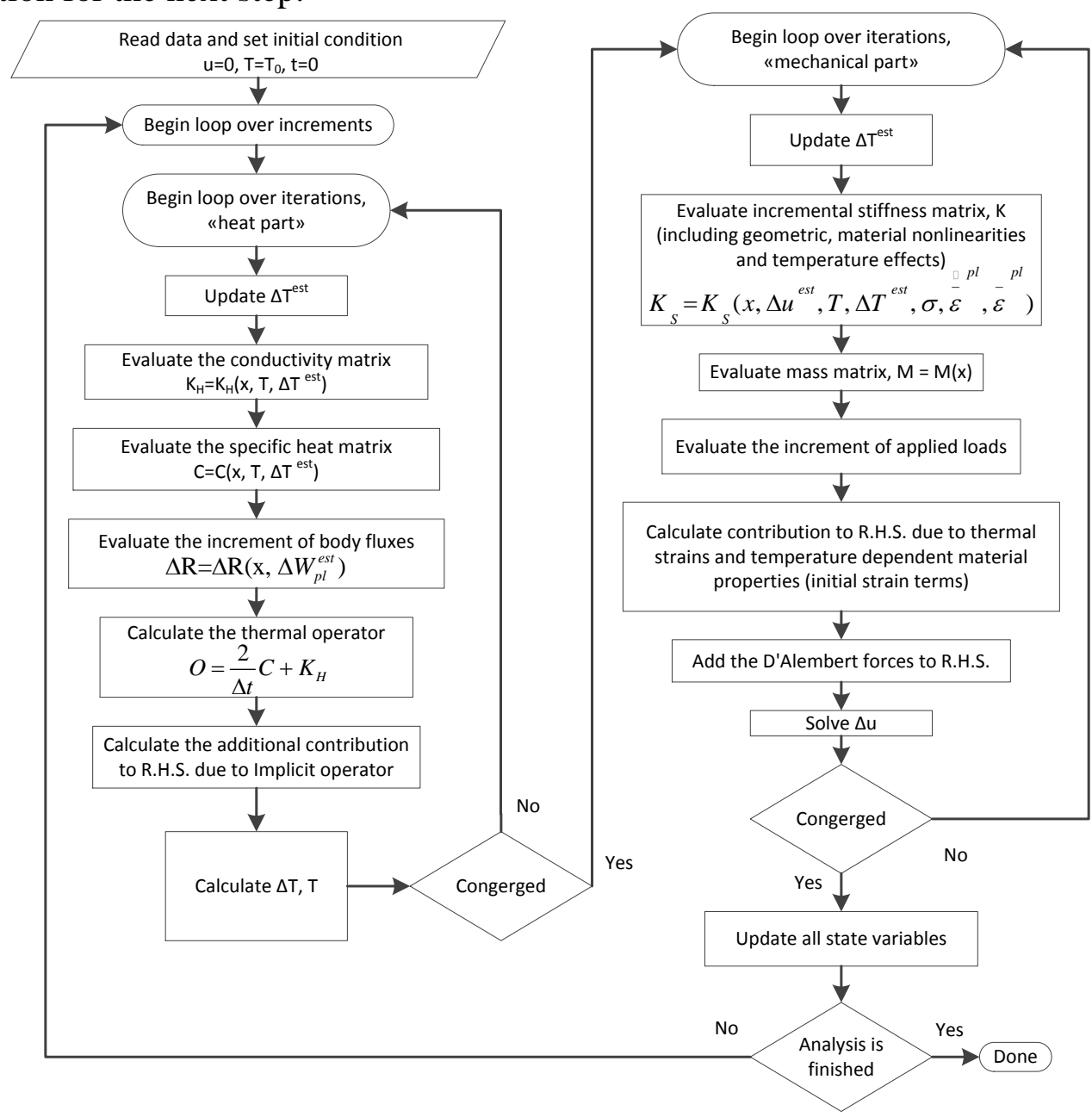

Fig. 5: The flowchart of coupled thermomechanical analysis from (MSC Software, 2013); the "est" in the chart is the abbreviation of "estimated". Calculation of all the state variables such as stress field and damage field are not mentioned in the flowchart. The stress field is calculated after calculation of the displacement. Damage field is also updated in each increment.

Initially, the equilibrium equation is written based on virtual work. In other words, a structure is in equilibrium under a given set of internal and external forces, if and only if, all kinematically admissible variations of the displacements that the virtual work done by the internal forces equals the virtual work done by the external forces:

$$
\int_{V} \sigma_{i j} \delta \varepsilon_{i j} d V=\int_{S} p_{i} \delta u_{i} d S+\int_{V} \rho f_{i} \delta u_{i} d V
$$

where $\sigma_{i j}$ is the Cauchy internal stress tensor, $\delta \varepsilon_{i j}$ is the virtual strain tensor, $p_{i}$ is the external pressure load vector, $\delta u_{i}$ is the virtual displacement vector, $\rho$ is the mass density, 
$\rho f_{i}$ is the external volume load vector, $V$ is the body volume and $S$ is the surface area subjected to pressure loads. Subsequently, since thermal effects are present, the energy balance can be stated as (Rao, 2011):

$$
\left.\rho \frac{\partial e}{\partial T}\right|_{\varepsilon_{i j}^{e}} \dot{T}-\left.T \frac{\partial \sigma_{i j}}{\partial T}\right|_{\varepsilon_{i j}^{e}} \dot{\varepsilon}_{i j}^{e}=\sigma_{i j} \dot{\varepsilon}_{i j}^{p}-\frac{\partial q_{i}}{\partial x_{i}}+Q
$$

in which $e$ is the internal energy, $\dot{\varepsilon}_{i j}^{e}$ is the rate of change of the elastic strain tensor, $\dot{\varepsilon}_{i j}^{p}$ is the rate of change of the plastic strain tensor, $\partial q_{i} / \partial x_{i}$ is the divergence of the heat flux vector at every point in the volume and $Q$ is the internal heat production per unit volume other than dissipative mechanical work. Through an incremental procedure, the system of (1) and simplified (2) can be solved resulting in the temperature and displacement fields. Discretization of field equations due to nonlinear constitutive equations, leads to nonlinear algebraic equations which must be linearized in further step. The coefficient matrix of linear algebraic equations is large and sparse. To tackle this problem, the Pardiso Direct Sparse matrix-solver is used on shared memory multiprocessors. Details of this method can be found in (MSC Software, 2013; Naumann, 2012; Østerby and Zlatev, 1983).

In terms of the kinematics of elastic and large plastic strains, the multiplicative decomposition of deformation gradients in a plastic and thermoelastic part is used. Then the stress is calculated by a radial return mapping procedure to the yield surface. A multistage return mapping method is used to return the stress to the yield surface. The detailed algorithm of multistage return mapping for elasto-plasticity in each increment of Cauchy stress is explained in (MSC Software, 2013). Furthermore, researchers such as (Chatti, 2010) have used the multiplicative decomposition in springback evolution.

In implicit coupled thermomechanical analysis, the temperatures are integrated using a backward-difference formula (BDF), and the nonlinear coupled system is solved using Newton's method. Numerical integration methods based on BDFs give an approximation to a derivative of a variable at a time $t_{n}$ in terms of its function values $y(t)$ at $t_{n}$ and earlier.

Choosing Newton's method to solve the nonlinear coupled equilibrium equations is primarily attributed to its faster convergence rates compared to alternative methods such as modified Newton or quasi-Newton methods. To describe the formulation of Newton's method, the equilibrium equation obtained by discretizing the virtual work equation can be written symbolically as:

$$
\underline{F}^{N}\left(\underline{u}^{M}\right)=0
$$

where $\underline{F}^{N}$ is the force component, for instance cutting force, conjugate to the $N^{t h}$ variable. Furthermore, $\underline{u}^{M}$ is the value of the $M^{t h}$ variable, for instance the value of displacement of the workpiece nodes, in which the "th" upper indices indicates the ordinal number of the variables. To solve (3) and find $\underline{u}^{M}$, it is assumed that after an iteration $\mathrm{i}$, an approximation to the solution is obtained. As explained in (Abaqus, 2014), by assuming $c_{i+1}^{M}$ as the difference between this solution and the exact solution, (3) can be written as:

$$
\underline{F}^{N}\left(\underline{u}_{i}^{M}+c_{i+1}^{M}\right)=0
$$

Then after expanding (4) in a Taylor series with respect to $\underline{u}_{i}{ }^{M}$, which is the approximate solution in iteration $\mathrm{i}$, gives the following: 


$$
\underline{F}^{N}\left(\underline{u}_{i}^{M}\right)+\frac{\partial \underline{F}^{N}\left(\underline{u}_{i}^{M}\right)}{\partial \underline{u}^{P}} c_{i+1}^{P}+\frac{\partial^{2} \underline{F}^{N}\left(\underline{u}_{i}^{M}\right)}{\partial \underline{u}^{P} \partial \underline{u}^{Q}} c_{i+1}^{P} c_{i+1}^{Q}+\ldots=0
$$

All the above terms except the two first terms can be neglected; in case $\underline{u}_{i}^{M}$ is a close approximation to the solution, which makes the magnitude of each $c_{i+1}^{M}$ small. Thus, it leads to a linear system of equations:

$$
\underline{K}_{i}^{N P} c_{i+1}^{P}=-\underline{F}_{i}^{N}
$$

where

$$
\underline{K}_{i}^{N P}=\frac{\partial \underline{F}^{N}\left(\underline{u}_{i}^{M}\right)}{\partial \underline{u}^{P}}
$$

is the Jacobian and

$$
\underline{F}_{i}^{N}=\underline{F}^{N}\left(\underline{u}_{i}^{M}\right)
$$

the next approximation to the solution is then:

$$
\underline{u}_{i+1}^{M}=\underline{u}_{i}^{M}+c_{i+1}^{M}
$$

Newton-Raphson with strain correction is used which is a variant of the Newton method and uses a linearized strain calculation, with the nonlinear portion of the strain increment applied as an initial strain increment in subsequent iterations. More details can be found in (MSC Software, 2013). In addition, the solution of non-positive definite system is forced to tackle the structural instabilities during the machining process due to a change in workpiece geometry and form of the chip.

An implicit, single-step Houbolt time integration is used to obtain the solution for nonlinear machining dynamics since it is unconditionally stable, second order accurate and asymptotical annihilating. After writing the general form of the single-step Houbolt algorithm from (Chung and Hulbert, 1994), and explaining the displacement, velocity and acceleration with respect to the current and next time step, the number of independent algorithmic parameters are reduced. One way to reduce the number of independent algorithms is imposing the asymptotic annihilation condition in order to have zero magnitude for roots of the characteristic polynomial in the high frequency limit. Further details about this algorithm is mentioned in (Chung and Hulbert, 1994).

\subsection{Geometrical nonlinearity}

Geometrical nonlinearity and mesh distortion are one of the major challenges in finite element simulation of processes involving large deformations and especially in machining with large negative rake angle. Lagrangian formulation can describe the geometrical nonlinearity in which the mesh is attached to the material elements. However, the magnitude of deformation is limited to distortion of the elements. In very large deformations such as in machining processes, Lagrangian meshes completely distort, so that the approximation of the continuum mechanical solution is no longer well represented. The problem of mesh distortion in Lagrangian formulation can be solved by considering the deformed material as the reference state for the next increment and overcome the problem of mesh distortion by rezoning/remeshing techniques. One of the solutions concerning the reference configuration, which is used in the present study, is the updated Lagrangian method, in which the current configuration acts as the reference state. Then the stiffness matrices are calculated based on the current deformed configuration. 
In the updated Lagrangian formulation, the stiffness matrix can be derived by linearization of (1) (MSC Software, 2013):

$$
\left\{\underline{K}_{1}+\underline{K}_{2}\right\} \underline{u}=\underline{F}-\underline{R}
$$

where $\underline{F}$ are the external forces, $\underline{R}$ are the internal forces, $\underline{\underline{K}}_{1}$ is the material stiffness matrix and $\underline{\underline{K}}_{2}$ is the geometric stiffness matrix. $\underline{\underline{K}}_{1}$ can be calculated from (MSC Software, 2013):

$$
\left(\underline{K}_{1}\right)_{i j}=\int_{V_{n+1}} \underline{\beta}_{i m n} \underline{l}_{m n p q} \underline{\beta}_{p q j} d V
$$

in which $\underline{\beta}_{i m n}$ is the symmetric gradient operator which is evaluated in the current configuration and $\underline{l}_{m n p q}$ is the material moduli tensor in the current configuration. $\underline{\underline{K}}_{2}$ can be calculated from (MSC Software, 2013):

$$
\left(\underline{K}_{2}\right)_{i j}=\int_{V_{n+1}} \underline{\sigma}_{k l} \underline{N}_{i, k} \underline{N}_{j, 1} d V
$$

in which $\underline{\sigma}_{k 1}$ is the Cauchy stress and $\underline{N}_{i, k}$ is the shape function gradient matrix.

Rezoning/remeshing, as explained in (Borouchaki et al., 2005), is one of the many solutions to overcome the problem of mesh distortion. In this method, the current state of deformation, strains, stresses, temperatures etc. are transferred by interpolation of field functions to the new mesh consisting of a different number of elements, and the analysis continues. Two of the algorithms that can be applied to transfer the state variables to new mesh are explained in (Ortiz and Quigley Iv, 1991; Perić et al., 1996). The common algorithm is to first project the history variables which are related to Gauss points onto the nodes within the deformed mesh. Secondly, interpolate the data within the mesh by shape functions. Thirdly, searching to which integration point and associated element in the previous distorted mesh, this new integration point is closest. Fourthly, interpolating the data at the new nodes in the new mesh by shape function and mapping the history variables at new Gauss points of the new mesh.

In place of contact, the new mesh searches for new contact and corrects the nodal positions to prevent the penetration of the two bodies. The penetration is measured from the center of each boundary element face to the contacting surface. Remeshing is carried out if the penetration is greater than twice the contact tolerance needed to form the chip during the machining process, and is also less than the target element size to accurately define the curvature of new contact bodies before contact. In addition to the penetration criterion, other remeshing criterion that is used in the present simulation is based on the element volume ratio to measure the flatness of the 3D element and to mitigate sharp corners on hexahedral elements. Thus, in the present study any element's aspect ratio smaller than 0.1 forces the analysis to perform remeshing. Another criterion that evaluates element distortion is the change of equivalent strain from the previous remeshing in any element of workpiece. Therefore, the strain change of 0.4 from the previous remeshing dictates the need to remesh. In addition, local refinement in global remeshing is considered to reduce computational costs.

It is found that for simulations concerning chip formation with large negative rake angle, 3D Patran ${ }^{\circledR}$ tetrahedral meshes can describe well the rubbing process. But it is ascertained that the physics of the chip formation process can be better described with 3D hexahedral remeshing which is based on the overlay technique. The overlay technique is explained in detail by (Samet, 1990). It is based on using a grid that encompasses the volume to be meshed. After intersecting the background grid with the geometry, the elements that are inside 
the geometry will be kept. Thus, it uses the predefined general dimension of mesh in the coordinate system, instead of seeding the surface of the geometry to generate the mesh. After defining the general size of the mesh, the mesh is generated from the inside to the outside of the volume. In this method, the initial mesh is generated using either a Cartesian, cylindrical or with a predefined grid type to adapt the inner mesh to the prescribed element size. In the present study, the Cartesian grid type is used. The positioning of the deformable part relative to the coordinate system is important and influences the mesh and accuracy of the surfaces. For instance the six surfaces describing the workpiece should be parallel to their corresponding planes of the Cartesian coordinate system. After generating the initial grid mesh, the mesh is projected onto the surfaces of the geometry to capture the boundary of the domain in order to fill the gap that is initially left between the mesh and the surface,

It is found that the gap parameter in 3D hexahedral remeshing plays a key role in chip morphology and influences the efficiency of the mesh generation algorithm. The gap parameter defines the gap that is left between the inner hexahedral elements and the surface of the workpiece during the remeshing procedure. Shaking is another parameter in the global remeshing procedure, which helps the nodes to move to the locations with less potential energy. In other words, shaking has a relaxing effect on the nodes and results in better mesh quality. Although shaking helps the formation of the chip, it is computationally expensive. Therefore, optimized shaking times should be considered in the simulation. Since the process of chip formation during single grain grinding is complex, particularly in regions where the edges of the diamond are in contact with workpiece or where the chip tends to curl, the remeshing algorithm does not always produce a valid mesh in the first run. Therefore, it is necessary to allow remeshing to restart with smaller element sizes to create suitable meshes in the workpiece. Furthermore, it is ascertained that the topography of the ground workpiece and the realistic shape of the chip could be achieved by allowing the formation of wedge elements in the workpiece. When remeshing complex geometries undergoing large deformations, it is important to consider in all the global remeshing algorithms the possibility of the loss of the volume. Several techniques are used to tackle this problem. One of them is to project Coons Patches of 3D deformed surfaces to the new surface in large geometrical nonlinearities. Coons Patches projection also results in better approximating the geometry of the deformed workpiece. Another important parameter which influences the correct representation of the workpiece following large deformations during the remeshing process, is edge sensitivity. Edge sensitivity in edge detection processes specifies when the new edges should be detected which represents the new form of the geometry after large deformation. In other words, it is a measure when the edge between the two elements represents a real edge. It is found that owing to the complexity of the process, when considering high edge sensitivity, the mesher fails to re-mesh and represent the nonlinearity of the process. Also when considering low edge sensitivity, the mesher cannot correctly represent the topography of the ground workpiece and the chip.

Geometric nonlinearity and realistic results, which describe the physics of the process, cannot be achieved without considering the proper element type in the simulation. Firstly, to reduce the computational costs, linear elements and fine mesh sizes are defined at regions of interest while everywhere else coarse mesh sizes are defined. Secondly, workpiece size dependencies on the results are studied. The workpiece is modeled with eight-noded, isoparametric, three-dimensional brick elements with trilinear interpolation. Each of these eight nodes has three translational and one heat transfer degree of freedom. This element uses eight-point Gaussian integration to form the stiffness of the element. To reduce the computational costs, low order elements are used. For elements with trilinear interpolation 
function, the strains tend to be constant through the element which is not an adequate representation of shear behavior in the case of having coarse elements. Moreover, to overcome the problem of constant strain through the element, a strain interpolation formulation is applied which improves the shear or bending characteristic of the element. It is found that in the case of using elements with full integration points for the workpiece, there is a possibility of element distortion, element inside out and problem in stress recovery in one of the integration points. Therefore, elements with reduced integration points are used. Furthermore, this element type has an additional contribution to the stiffness matrix to eliminate problems associated with hourglass modes. The diamond is modeled as a rigid body with temperatures as nodal degrees of freedom. Planar quadrilateral elements are applied to the rigid diamond, which are four-node isoparametric elements with bilinear interpolation. This element has four-point Gaussian integration for the plane.

\subsection{Material modeling}

The Johnson-Cook material model (Johnson and Cook, 1983) is used to describe strain hardening, strain rate sensitivity and thermal softening of the workpiece and chip in the machining process. The model describes the flow stress as a function of three terms, namely elastoplastic, viscosity and thermal softening:

$$
\begin{aligned}
& \sigma=\left[A+B\left(\varepsilon^{p}\right)^{n}\right]\left[1+C \ln \dot{\varepsilon}^{*}\right]\left[1-T^{* m}\right] \\
& \dot{\varepsilon}^{*}=\frac{\dot{\varepsilon}^{p}}{\dot{\varepsilon}_{0}} \\
& T^{* m}=\frac{T-T_{0}}{T_{m}-T_{0}}
\end{aligned}
$$

where $\varepsilon^{p}$ is the equivalent plastic strain, $\dot{\varepsilon}^{*}$ is the equivalent strain rate for reference strain rate of $\dot{\varepsilon}_{0}=1 s^{-1}, \dot{\varepsilon}^{p}$ is the plastic strain rate and $T^{* m}$ is the homologous temperature which is a function of the melting temperature, $T_{m}=1723 \mathrm{~K}$ and room temperature, $T_{0}$. The five material constants of $\mathrm{A}, \mathrm{B}, \mathrm{C}, \mathrm{n}$ and $\mathrm{m}$ are the quasi-static yield strength of the material, hardening modulus, strain rate sensitivity coefficient, work-hardening index and thermal softening index respectively. The value of these parameters are taken from (Khan et al., 2004) for Ti-6Al-4V. The sensitivity of the simulations to different parameters which are mentioned in (Khan et al., 2004) are analyzed and in the present study, the parameters mentioned in Table 1 are used.

\begin{tabular}{|c|c|c|c|c|}
\hline A [MPa] & B [MPa] & C & $\mathrm{n}$ & $\mathrm{m}$ \\
\hline 1104 & 1036 & 0.01390 & 0.6349 & 0.7794 \\
\hline
\end{tabular}

Table 1: Johnson-Cook parameters for Ti-6Al-4V which represent the physics of single diamond machining.

The conversion of a part of mechanical energy into thermal energy and as a result the determination of volumetric and surface heat generation needs to be considered. One source of surface heat is frictional heat generated at the sliding interface. Volumetric heat generation due to plastic deformation is another source of generated heat. The inelastic heat fraction (IHF) parameter, also known as the Taylor-Quinney constant, is used to define the main fraction of plastic work converted into heat. This determines the temperature rise and the minute fraction of the energy that is stored in the material. The generated heat is treated as a volumetric and surface heat flux source term in the heat balance equation. Plastic straining, according to (Abaqus, 2014), gives rise to a heat flux $r^{p}$ per unit volume: 


$$
r^{p}=\eta \underline{\underline{\sigma}}: \underline{\underline{\varepsilon}}^{p}
$$

where $r^{p}$ is added into the thermal energy balance and $\eta$ is the IHF material parameter. The IHF for metals is between 0.8 to 1 and for Ti-6Al-4V and the value of 0.9 is used.

During machining, the temperature can rise to more than half the melting temperature of the workpiece depending on the process parameters and materials. The rise of the temperature during machining changes the damage behavior and acts as recovery and recrystallization. To explain mechanical damage as mentioned in detail by (Dieter, 2003), the compressive stress state closes up any porosity or pipe and hinders any inclusions or segregation from initiating cracks. Therefore, a relationship between damage and stress/strain state should be considered in the material modeling of the workpiece to address the fracture strain and thermal softening. To consider a damage model that can describe the physics of machining with large negative rake angle, some common damage models are discussed in the following. One approach to explain the damage behavior is by using the damage criteria of Cockcroft-Latham and Oyane Damage Indicator. These damage criterions do not affect the yield stress. It is a postprocessing value to indicate a possible damage area. Damage can also be used to define a sacrificial layer and separate the chip from the workpiece. In metal machining simulations, damage can be used to predict the effect of tensile stress on the chip segmentation. In these models, for example as in (Umbrello et al., 2008), upon reaching the critical damage value for each element, the element and its connectivity is deleted. Using smoothing algorithms, remeshing and rezoning methodologies, a serrated chip is formed as a result of local softening and instability. However, in the case of using this criterion for machining with large negative rake angles, the entire chip is considered as damage and essentially will be fully deleted.

Comparing to other damage models, Johnson Cook damage criterion as explained in (Johnson and Cook, 1985) can better describe local softening using pressure-, strain rate- and temperature-dependent parameters. Therefore, a Fortran damage subroutine named UDAMG, is written in the general-purpose nonlinear finite element MSC-Marc ${ }^{\circledR}$ software to define the Johnson Cook damage criterion. The strain at fracture, based on (Johnson and Cook, 1985), is calculated by:

$$
\varepsilon^{f}=\left[D_{1}+D_{2} \exp \left(D_{3} \sigma^{*}\right)\right]\left[1+D_{4} \ln \left(\frac{\dot{\varepsilon}^{p}}{\dot{\varepsilon}_{0}}\right)\right]\left[1+D_{5} T^{*}\right] \quad \sigma^{*}=\frac{p}{\bar{\sigma}}
$$

where $D_{i}, i=1, \ldots, 5$ are the material parameters and $\sigma^{*}$ is the triaxiality which is the ratio of hydrostatic pressure $p$, divided by von Mises equivalent stress $\bar{\sigma}$. Due to large computation time of 3D coupled thermomechanical analysis, the simulations with a variation of five damage variables as design variables are carried out in parallel and three cutting forces as well as temperature field as design objective. The optimized Johnson Cook damage parameters for machining with negative rake angle are specified in Table 2 . With these parameters, the temperature field and cutting force components are fitted with experimental values:

\begin{tabular}{|c|c|c|c|c|}
\hline $\mathrm{D}_{1}$ & $\mathrm{D}_{2}$ & $\mathrm{D}_{3}$ & $\mathrm{D}_{4}$ & $\mathrm{D}_{5}$ \\
\hline-0.09 & 1 & 0.48 & 0.014 & 3.87 \\
\hline
\end{tabular}

Table 2: Johnson-Cook damage parameters for Ti-6Al-4V.

The first bracket of (15) signifies that the strain at fracture decreases as the hydrostatic pressure increases. The second and third bracket of (15) describes the effect of an increased strain rate and the effect of thermal softening on the material ductility respectively. The 
evolution of damage is described with a damage variable $d_{f}$. This is given by the accumulated incremental equivalent plastic strain $\Delta \varepsilon^{p}$, divided by the strain at fracture $\varepsilon^{f}$ under the present condition of strain rate, temperature, hydrostatic pressure and stress:

$$
d_{f}=\sum \frac{\Delta \varepsilon^{p}}{\varepsilon^{f}}
$$

in which $d_{f}$ is the damage variable; Thus the flow stress $\sigma_{y}$ of the damaged structure is calculated from:

$$
\sigma_{y}=\sigma\left(1-d_{f}\right)
$$

in which $\sigma$ is the von Mises flow stress in (13). Furthermore, the Young's modulus $E$ after damage changes to $E_{y}$ through:

$$
E_{y}=E\left(1-d_{f}\right)
$$

In the constitutive equations of (15), (16), (17) and (18) fracture occurs when the damage variable $d_{f}$ equals the limit value of one. In metal machining process with large negative rake angle, because of high compressive cutting forces and also high cutting temperature, material at the root of the chip, degrades and damage happens, but the material does not fracture. In addition, the behavior of material in this region has a high influence on cutting forces and temperature. It can be interpreted as a change in damage behavior, re-joining of microvoids/cracks, change in the microstructure due to high compressive cutting forces from the negative rake face of the cutting tool and recrystallization due to high temperatures in the cutting zone. It can also be attributed to the fact that in metal machining process with large negative rake angle, as the hydrostatic pressure increases, the strain to damage decreases slower than other situations in which the material parameters are derived. Therefore in (16), $d_{f}$ does not reach one and the workpiece does not fracture completely. Moreover, the Johnson Cook damage parameters in Table 2 and (15) are normally measured and calculated for other processes other than machining process with large negative rake angles. Thus to find out the damage limit of $d_{f l}$ and also the damage parameters in Table 2 and. (15), a set of simulations for different set of parameters are carried out and the calculated cutting forces and cutting temperatures are compared with experimental results. A damage limit, $d_{f l}$ of 0.7 and the damage parameters in Table 2 are considered. The general form of the chip, simulated cutting forces in Fig. 7, and cutting temperature in Fig. 8 are validating with experimental results and are shown in section 4.

Material modeling without a correct friction law does not model the physics of the machining process properly. Friction mainly depends on surface roughness, relative velocity, temperature and stress. In the contact region between the diamond and the workpiece where there is a tangential movement between the two surfaces, shear stresses due to friction arise. One of the solutions to model this phenomenon is defining a critical stress value, which describes the starting point of sliding between the two surfaces. With this modified Coulomb friction model, the amount of friction due to plastic deformation can be limited and does not exceed the shear yield stress of the material. Therefore, the friction model correlates better with the experiment. In the bilinear friction model which is used in the present study, stick and slip conditions of the tool and workpiece are related to reversible (elastic) and permanent (plastic) relative displacements, respectively. The following criterion for slippage is applied (MSC Software, 2013): 


$$
\left\{\begin{array}{lr}
\Phi=\left\|F_{t}\right\|-\mu \underline{F}_{n}<0 & \text { S t i c k } \\
\Phi=\left\|F_{t}\right\|-\mu F_{n}=0 & \text { S li p }
\end{array}\right.
$$

in which $\Phi$ is the slip tolerance, $\mu$ is the friction coefficient, $\underline{F}_{n}$ is the normal force and $\underline{F}_{t}$ is the friction force. The rate of the tangential relative incremental displacement $\dot{\mathrm{u}}_{t}$ is the sum of the elastic (sticking) rate of the incremental displacement $\dot{\mathbf{u}}_{t}^{e}$, and plastic (slipping) rate of the incremental displacement $\dot{\mathrm{u}}_{t}^{p}$. The friction coefficient, as stated in (Furrer and Semiatin, 2010), can be written as a function of temperature, pressure, sliding velocity and surface roughness. In the present study, the influence of temperature on the friction coefficient is not considered. The value of the friction coefficient has been reported as 0.2 in (Klaus Bewilogua, 2002) and 0.7 in (Aurich and Bil, 2006). It is found that by using a friction coefficient of 0.6, simulated and experimental results are comparable.

To solve the physically impossible situation in which $\Phi>0$, maintain sufficient numerical stability and improve the rate of convergence, the rate of tangential friction force is needed. With considering $\underset{\underline{\Gamma}}{=}$ through (MSC Software, 2013):

$$
\underline{\underline{\Gamma}}=\left[\begin{array}{cc}
\frac{\mu \underline{F}_{N}}{\delta} & 0 \\
0 & \frac{\mu \underline{F}_{N}}{\delta}
\end{array}\right]
$$

where, $\delta$ is the slip threshold which is 0.0025 times the average length of the elements in the deformable contact body. The rate of tangential friction force is calculated from (MSC Software, 2013):

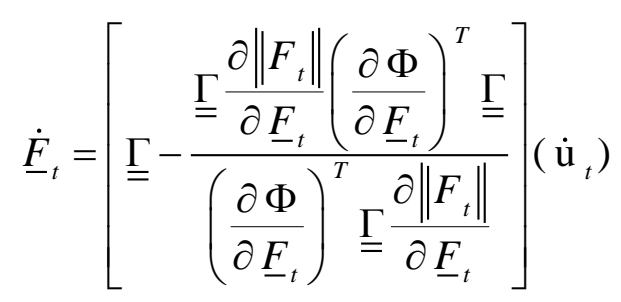

where, $\left\|F_{t}\right\|$ shows the assumption that the direction of the slip displacement rate is given by the normal to the slip flow potential. Finally, an additional check is applied to determine the convergence of the friction force by (MSC Software, 2013):

$$
\frac{\|\| F_{t}\|-\| F_{t}^{p r} \| \mid}{\|F\|_{t}} \leq e
$$

in which $\underline{F}_{t}{ }^{p r}$ is the friction force of the previous iteration and $e$ is a user defined tolerance which is considered as 0.05 .

\subsection{Thermal modeling}

Thermal modeling has a substantial influence on the mechanical state variables and the overall response of the model. Therefore meticulous handling of thermal effects is necessary. Grinding generates a steady state of temperature and to remove the heat, a specific cooling procedure can be applied. However in the present experimental setup, all the system commence from room temperature. Therefore initial temperature of $293 \mathrm{~K}$ according to (ISO, 
2002) is considered. An overview of the thermal boundary conditions is illustrated in Fig. 6. The body of the tool which is bonded to the diamond grain is modeled as a rigid body and since cutting occurs over a very short period, a Dirichlet boundary condition of $300 \mathrm{~K}$ is considered for the tool. The fixture is modeled as two rigid surfaces in the bottom and at end of the workpiece with a Dirichlet boundary condition of $293 \mathrm{~K}$. To reduce the computational costs it is assumed that the nodal temperature of the fixture and the nodes of the workpiece which are in contact with the fixture, have the same temperature degrees of freedom. Free convection heat transfer between the diamond and air as well as between the workpiece and air is considered using a convection heat transfer coefficient of $30 \mathrm{~W} / \mathrm{m}^{2} \mathrm{~K}$ (Furrer and Semiatin, 2009). Heat conduction between the diamond and workpiece as well as inside the workpiece is considered. It is assumed that the conductivity of the diamond and the workpiece are not temperature dependent and based on (Furrer and Semiatin, 2009), a thermal conductivity of $2000 \mathrm{~W} / \mathrm{mK}$ and $43 \mathrm{~W} / \mathrm{mK}$ is assigned to the diamond and Ti-6Al-4V respectively. In addition, since the time of the machining process is short and the size of the diamond is small, radiation is neglected.

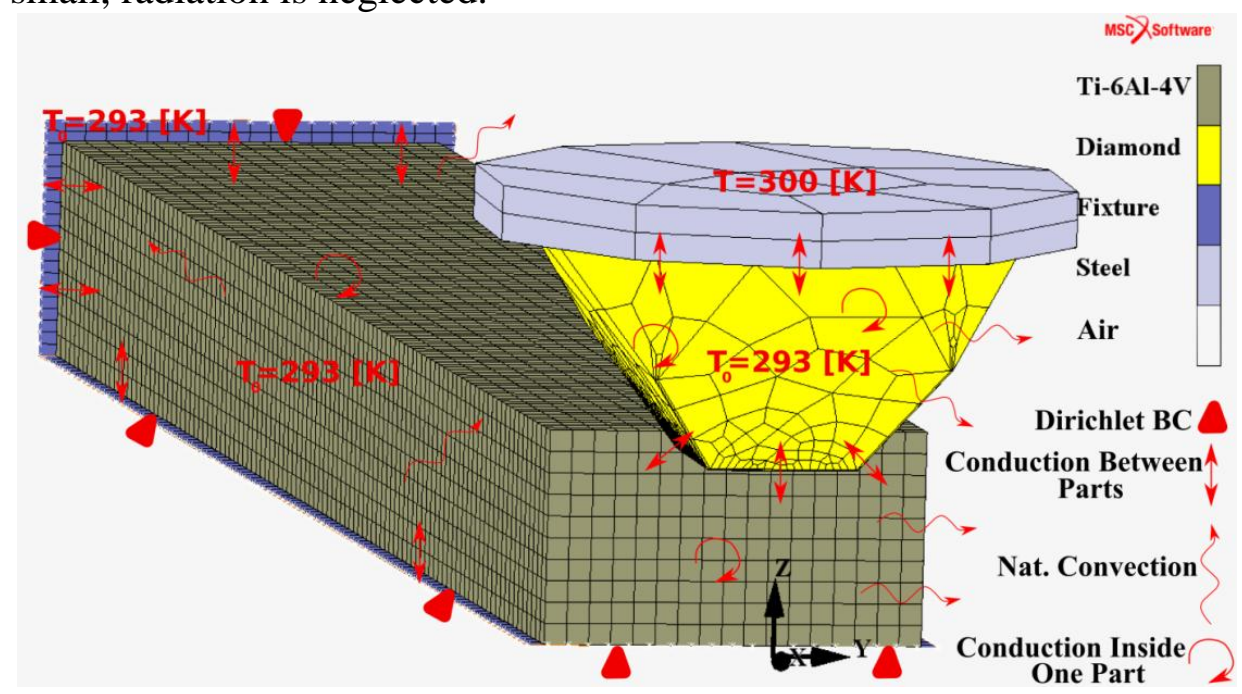

Fig. 6: Overview of the thermal boundary conditions.

\section{Comparison of simulation and experiment}

In the simulation, a Ti-6Al-4V workpiece with a length of greater than $3 \mathrm{~mm}$ is cut by a diamond exhibiting a $0.27 \mathrm{~mm}$ cutting edge length. The simulation time is derived from the length of the workpiece over the cutting speed. Cutting forces reach steady state after full penetration of the brazed diamond cutting tool into the workpiece and after a $0.5 \mathrm{~mm}$ length of cut, the results are plotted. The main objective of the optimization is the cutting force according to the design variables of the damage limit and damage parameters given in (15). Thus, as seen in Fig. 7, the cutting force is the same as in the experiment. The passive force is lower while the normal force is higher than the exact value of the experimental values. However, they are within the range of the uncertainty of the experiment as explained in section 2.3 . 


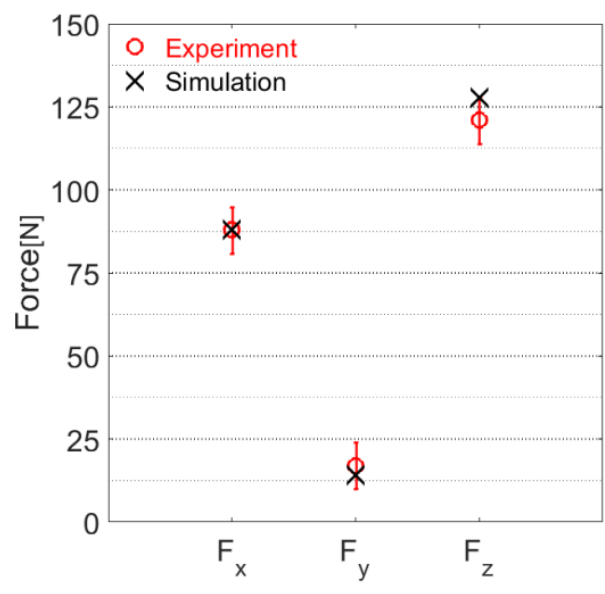

Fig. 7: Numerical and experimental cutting forces, $F_{x}$, passive force, $F_{y}$, and normal force, $F_{z}$, for cutting speed of $0.8 \mathrm{~m} / \mathrm{s}$ and $30 \mu \mathrm{m}$ depth of cut. The coordinate system is shown in Fig. 8.

Thermal measurements are carried out based on the details in section 2.4 and thermal modelling is carried out according to section 3.4. The results in Fig. 8 show the simulated and experimented temperature field during a single grain machining test. The simulated results in Fig. $8 \mathrm{~b}$ are comparable to the IR-thermography measurements in Fig. 8a, however, the flash temperature in the cutting edge which is inside the material cannot be detected by IRthermography. Thus in the simulation results, higher temperatures are noticeable. With this method, the detection of the temperature field of the machining process from all sides, even from the base of the chip where the diamond face transmits infrared light to the detectors below the rake face is possible. However, the diamond grain in experimental results, Fig. 8a, is much cooler than in simulation results, Fig. $8 \mathrm{~b}$, which could be due to the machine tool acting as a thermal sink.
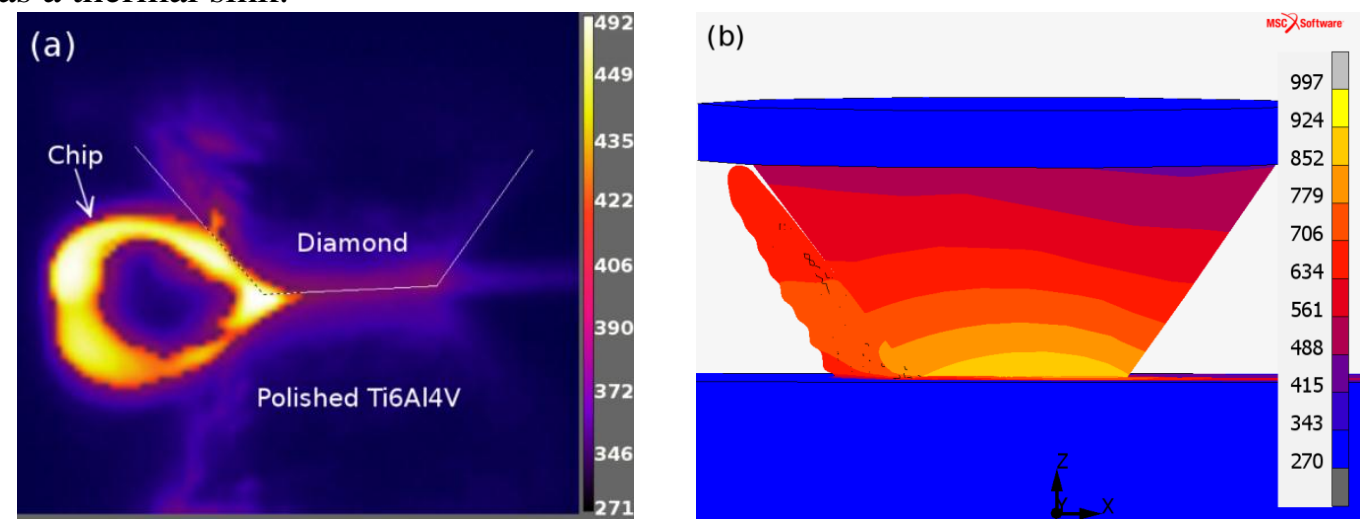

Fig. 8: (a) IR-thermography of the machining process at a cutting speed of $0.8 \mathrm{~m} / \mathrm{s}$ and $30 \mu \mathrm{m}$ depth of cut; the surface of the diamond is defined with lines. (b) 3D simulated temperature; a cutting edge radius of $7 \mu \mathrm{m}$ is considered based on (Akbari et al., 2016). This image is selected to show that the simulated chip separates from the diamond. The highest temperature inside the cutting zone can be simulated and cannot be detected by IRthermography.

\section{Influence of cutting edge radius}

It is proved experimentally by (Wyen and Wegener, 2010) that cutting forces reduce for sharper cutting edges. Therefore, the behavior of the code from a theoretically very sharp cutting edge radius of $0 \mu \mathrm{m}$ to a very large cutting radius of $20 \mu \mathrm{m}$ is investigated. In this analysis, the cutting speed, depth of cut and clearance angle, are set to $0.8 \mathrm{~m} / \mathrm{s}, 30 \mu \mathrm{m}$ and $0^{\circ}$ respectively. The sensitivity of the cutting forces for two different cutting edge radii is 
presented in Fig. 9. In addition, the influence of cutting edge radius on the temperature field is depicted in Fig. 9a and Fig. 9b. It is predicted that machining with a sharp cutting edge generates lower temperatures. Flash temperature when machining with a $0 \mu \mathrm{m}$ cutting edge radius is $754 \mathrm{~K}$, while the flash temperature when machining with a $20 \mu \mathrm{m}$ cutting edge radius is $806 \mathrm{~K}$. Higher flash temperature machining from the use of a blunt tool arises from higher passive and normal forces. When machining with blunt tool, the efficiency reduces which leads to heat generation.

The size effect in machining refers to the increase in specific machining energy, at small values of undeformed chip thickness. This phenomenon can be derived from the ploughing force composed of forces acting on the tool edge and forces acting on the flank faces. Ploughing forces in machining with large undeformed chip thickness consists of a small portion of the cutting forces. However, in grinding where the undeformed chip thickness is small the difference between ploughing and cutting force is higher in comparison to machining with a large cutting depth. As stated in (Boothroyd and Knight, 2006), the ploughing force does not have a significant influence on the chip formation and mainly leads to waste of machining energy. In the present study, the influence of ploughing force and size effect is demonstrated by modelling the tool with a large cutting edge radius of $20 \mu \mathrm{m}$. Large cutting edge radii can also occur after prolonged use in a machining process owing to wear of initially sharp cutting edges. As shown in Fig. 9, the normal force increases for large cutting edge radii.
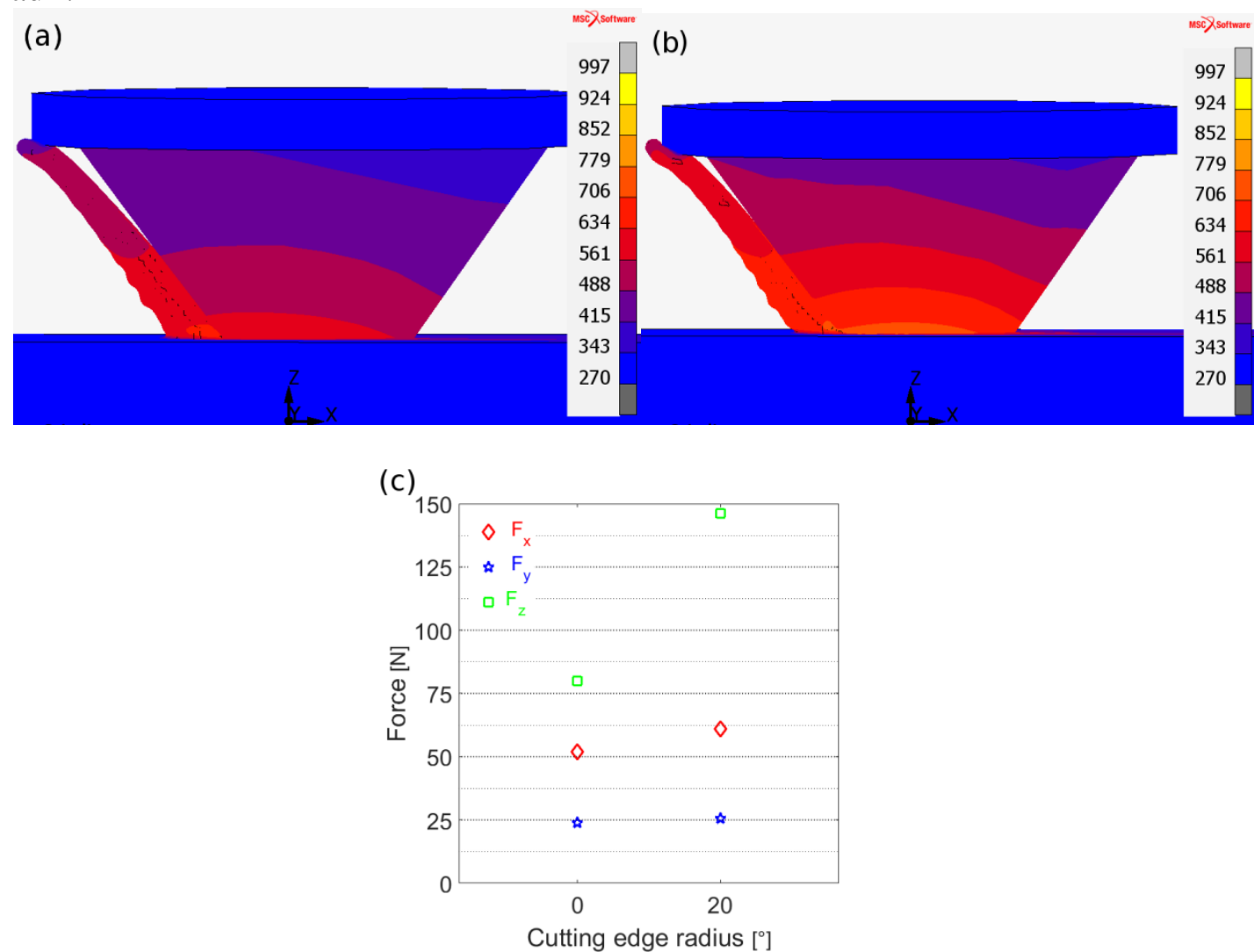

Fig. 9: The simulations results show the influence of two different cutting edge radii of 0 and $20 \mu \mathrm{m}$ for cutting speed of $0.8 \mathrm{~m} / \mathrm{s}$ and $30 \mu \mathrm{m}$ depth of cut. (a) shows the temperature field when machining with $0 \mu \mathrm{m}$ cutting edge and flash temperature of $754 \mathrm{~K}$ and (b) with $20 \mu \mathrm{m}$ cutting edge and flash temperature of $806 \mathrm{~K}$ for the same simulation time step. Influence of cutting edge radii of $0 \mu \mathrm{m}$ and $20 \mu \mathrm{m}$ on cutting forces is shown in (c).

Analyzing the field of damage variable helps to bring insight into surface integrity. Thus, in Fig. 10 field of damage for two different cutting edge radii of $0 \mu \mathrm{m}$ and $20 \mu \mathrm{m}$ halfway into 
the workpiece which is sliced with planes with distance of $80 \mu \mathrm{m}$ is shown. The simulations show that the initial depths of damage of the machined surfaces are $83 \mu \mathrm{m}$ and $68 \mu \mathrm{m}$ for a 20 $\mu \mathrm{m}$ and $0 \mu \mathrm{m}$ cutting edge radii respectively.
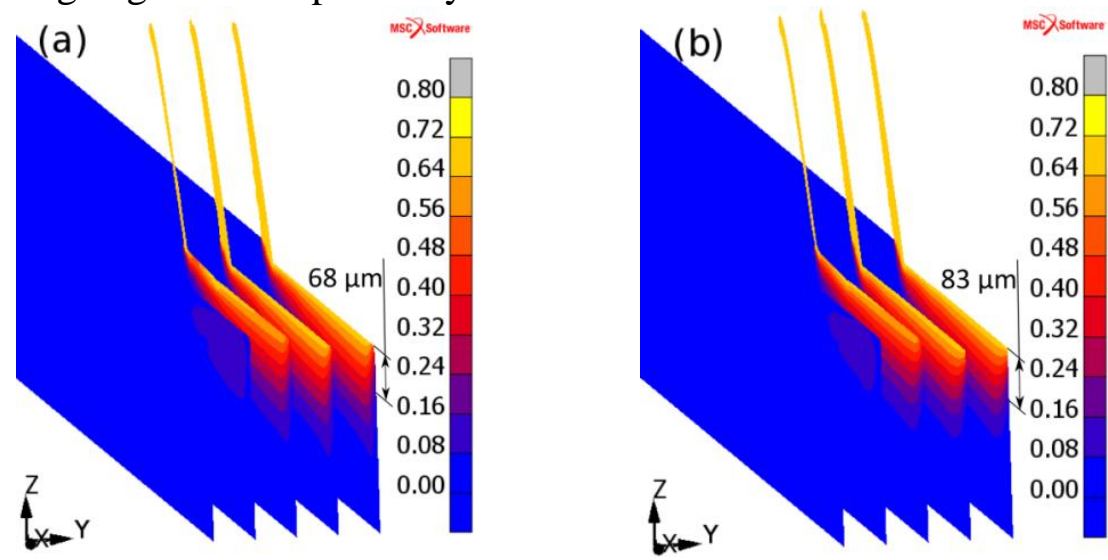

Fig. 10: Field of damage halfway into the 3D workpiece which is sliced into planes: (a) Machining with $0 \mu \mathrm{m}$ cutting edge radius and (b) Machining with $20 \mu \mathrm{m}$ cutting edge radius. The distance between each of the five sliced planes is $80 \mu \mathrm{m}$. Damage field in machining with $20 \mu \mathrm{m}$ cutting edge radius is around $15 \mu \mathrm{m}$ deeper than machining with $0 \mu \mathrm{m}$ cutting edge radius.

\section{Conclusions}

Grinding processes will only damage the surface integrity, if improper parameters are used i.e. dull tools, too high feed rates, large depth of cut, improper coolant, lubrication, or incorrect grinding tool hardness. To design a tool, optimize the process parameters or understand the physics of grinding, single grain machining tests can be used. When simulating the machining processing with large negative rake angles, the tool has the tendency to plough the workpiece material instead of forming a chip and demonstrating typical burr topography. That is due to highly compressive forces resulting from the flank face of the tool. With the help of suitable remeshing parameters, a physically correct representation of damage and friction modelling is achieved in the present study. Furthermore, the concept of using a value of damage limit $d_{f}$ smaller than one in a coupled thermomechanical model for the simulation of machining with negative rake angle is studied. It is found that when considering small damage limit values, for example 0.3 for Ti-6Al-4V, the material will be ploughed and the macroscopic form of the chip, cutting forces and temperature fields will not be comparable to experiments. For large damage limit values, the curling of the chip and very thin chip thicknesses occurs. Given experimental conditions where the tool is in full contact with the workpiece and the cutting forces reach steady state, the three components of the cutting forces were validated with experiment for a damage limit of 0.7.

Also as proved by (Akbari et al., 2016), the diamond grains have different cutting edge radii and it is important to understand the role of different cutting edge radii in simulation of machining. It is found that in machining with large negative rake angles, cutting and passive forces were reduced with sharper cutting edges. In addition, normal forces, $\mathrm{F}_{\mathrm{z}}$, were high for a large cutting edge radius, e.g. $20 \mu \mathrm{m}$, comparing to a sharp cutting edge radius, e.g. $0 \mu \mathrm{m}$. The passive forces, $\mathrm{F}_{\mathrm{y}}$, were due to non-symmetric grains and for very sharp and blunt tools were in the same range. Change of machining behavior due to wear pattern can also be explained by a variation of the cutting edge radius.

Deduced from this, grinding performance can be improved manifold: reducing the wear of the diamond grains and preferably utilizing grains with sharp cutting edges. Adjustable depth 
of cut, based on cutting forces to assure permissible load for the grains. In stochastic distribution of the grains, more grains with positive clearance angle lead to less cutting force and more chip formation instead of ploughing. In conclusion, the authors are confident that this technique will be used in the future to compute the influence of different rake angles, behavioral change of machining due to wear pattern, and grain pullout force in order to strengthen the binder-grain interface.

Acknowledgements The authors would like to thank the Swiss National Science Foundation for the financial support under project number 200021-117847, the High Performance Computing Center of ETHZ, support from the Electron Microscopy Centre EMEZ of ETHZ, Jens Boos, Prof. Pavel Hora, Dr. Fredy Kuster and Dr. Josef Mayr.

\section{References}

Abaqus, 2014. Abaqus 6.14-1 Theory Manual, Providence, RI, USA.

Akbari, M., Buhl, S., Leinenbach, C., Spolenak, R., Wegener, K., 2012. Thermomechanical analysis of residual stresses in brazed diamond metal joints using Raman spectroscopy and finite element simulation. Mechanics of Materials 52, 69-77.

Akbari, M., Knapp, W., Wegener, K., 2016. Comparison of Transparent Objects Metrology through Diamond Cutting Edge Radii Measurements. CIRP Journal of Manufacturing Science and Technology (Article In Press), (Available online 15 January 2016).

Anderson, D., Warkentin, A., Bauer, R., 2011. Experimental and numerical investigations of single abrasivegrain cutting. International Journal of Machine Tools \& Manufacture 51, 898-910.

Aurich, J.C., Bil, H., 2006. 3D Finite Element Modelling of Segmented Chip Formation. CIRP Annals Manufacturing Technology 55, 47-50.

Aurich, J.C., Dornfeld, D., Arrazola, P.J., Franke, V., Leitz, L., Min, S., 2009. Burrs-Analysis, control and removal. CIRP Annals - Manufacturing Technology 58, 519-542.

Aurich, J.C., International Academy for Production, E., Burrs, C.I.C.o., 2010. Burrs - analysis, control and removal. Springer-Verlag.

Blau, P.J., 1992. ASM handbook Volume 8: Friction, lubrication, and wear technology. ASM International.

Blok, H., 1963. The flash temperature concept. Wear 6, 483-494.

Boothroyd, G., Knight, W.A., 2006. Fundamentals of machining and machine tools. CRC.

Borouchaki, H., Laug, P., Cherouat, A., Saanouni, K., 2005. Adaptive remeshing in large plastic strain with damage. Int. J. Numer. Methods Eng. 63, 1-36.

Brinksmeier, E., Cammett, J.T., König, W., Leskovar, P., Peters, J., Tönshoff, H.K., 1982. Residual Stresses Measurement and Causes in Machining Processes. CIRP Annals - Manufacturing Technology 31, 491510.

Brinksmeler, E., Glwerzew, A., 2003. Chip Formation Mechanisms in Grinding at Low Speeds. CIRP Annals Manufacturing Technology 52, 253-258.

Buhl, S., 2012. Failure mechanisms of heavily-loaded brazed diamonds. VDI Verlag Gmbh Duesseldorf, Germany

Chang, C.-S., 2007. Prediction of the cutting temperatures of stainless steel with chamfered main cutting edge tools. Journal of Materials Processing Technology 190, 332-341.

Chatti, S., 2010. Effect of the elasticity formulation in finite strain on springback prediction. Comput. Struct. 88 , 796-805.

Childs, P.R.N., 2001. Practical temperature measurement. Oxford : Butterworth-Heinemann, Oxford.

Chung, J., Hulbert, G.M., 1994. A family of single-step Houbolt time integration algorithms for structural dynamics. Computer Methods in Applied Mechanics and Engineering 118, 1-11.

Cotell, C.M., Sprague, J.A., Smidt, F.A., 1994. ASM handbook, Volume 5 : Surface engineering. ASM International.

Davies, M.A., Ueda, T., M'Saoubi, R., Mullany, B., Cooke, A.L., 2007. On The Measurement of Temperature in Material Removal Processes. CIRP Annals - Manufacturing Technology 56, 581-604.

Dieter, G.E., 2003. Handbook of workability and process design. ASM International.

DIN, 2003. Fertigungsverfahren Spanen DIN 8589. Beuth Verlag GmbH - Deutsches Institut für Normung, Deutschland

Furrer, D., Semiatin, S.L., 2009. Fundamentals of Modeling for Metals Processing, Materials Park, OH 440730002.

Furrer, D.U., Semiatin, S.L., 2010. Metals process simulation. ASM International. 
Haddag, B., Kagnaya, T., Nouari, M., Cutard, T., 2013. A new heat transfer analysis in machining based on two steps of 3D finite element modelling and experimental validation. Heat and Mass Transfer 49, 129-145.

Hokka, M., Leemet, T., Shrot, A., Baeker, M., Kuokkala, V.T., 2012. Characterization and numerical modeling of high strain rate mechanical behavior of Ti-15-3 alloy for machining simulations. Materials Science and Engineering 550, 350-357.

Hou, Z.B., Komanduri, R., 2003. On the mechanics of the grinding process - Part I. Stochastic nature of the grinding process. International Journal of Machine Tools and Manufacture 43, 1579-1593.

ISO, 2002. Geometrische Produktspezifikation (GPS) Referenztemperatur für geometrische Produktspezifikation und prüfung, ISO 1. Internationale Organisation für Normung, p. 3.

Issa, M., Saanouni, K., Labergere, C., Rassineux, A., 2011. Prediction of serrated chip formation in orthogonal metal cutting by advanced adaptive 2D numerical methodology. Int. J. Mach. Machinability Mater. 9, 295-315.

Jackson, M.J., Hitchiner, M.P., 2013. High performance grinding and advanced cutting tools. Springer.

Johnson, G.R., Cook, W.H., 1983. A constitutive model and data for metals subjected to large strains, high strain rates and high strain rates and high temperatures, The 7th International Symposium on Ballistics, The Hague, The Netherlands, pp. 541-547.

Johnson, G.R., Cook, W.H., 1985. Fracture characteristics of three metals subjected to various strains, strain rates, temperatures and pressures. Engineering Fracture Mechanics 21, 31-48.

Karpuschewski, B., Binh, N.T., 2007. An Emperical Cutting-Force Model in High-Speed-Milling Process with Spherical Cutter. Technical University of Kosice, Výrobné inzinierstvo, 5-8.

Karpuschewski, B., Schmidt, K., Prilukova, J., Beňo, J., Maňková, I., Hieu, N.T., 2013. Influence of tool edge preparation on performance of ceramic tool inserts when hard turning. Journal of Materials Processing Technology 213, 1978-1988.

Khan, A.S., Sung Suh, Y., Kazmi, R., 2004. Quasi-static and dynamic loading responses and constitutive modeling of titanium alloys. International Journal of Plasticity 20, 2233-2248.

Klaus Bewilogua, G.B., 2002. Kohlenstoffschichten gegen Reibung und Verschleiß. Carolo-Wilhelmina 1, 3438.

Li, X.K., Rong, Y.M., 2011. Framework of grinding process modeling and simulation based on microscopic interaction analysis. Robotics and Computer-Integrated Manufacturing 27, 471-478.

Liu, G., Tan, G., Li, G., 2009. Experiment, modeling, and analysis for temperature field of milling insert. Int J Adv Manuf Technol 40, 67-73.

Liu, J., Chou, Y.K., 2007. Cutting tool temperature analysis in heat-pipe assisted composite machining. Journal of Manufacturing Science and Engineering-Transactions of the Asme 129, 902-910.

Lohkamp, R., Muller, R., Schneider, F., Aurich, J., 2012. Multiscale modelling and simulation of micro machining of titanium. Proceedings in Applied Mathematics and Mechanics 12, 311-312.

Mamalis, A.G., Manolakos, D.E., Markopoulos, A., Kunádrk, J., Gyáni, K., 2003. Thermal Modelling of Surface Grinding Using Implicit Finite Element Techniques. Int J Adv Manuf Technol 21, 929-934.

Matsuo, T., Toyoura, S., Oshima, E., Ohbuchi, Y., 1989. Effect of Grain Shape on Cutting Force in Superabrasive Single-Grit Tests. CIRP Annals - Manufacturing Technology 38, 323-326.

Minton, T., Ghani, S., Sammler, F., Bateman, R., Fürstmann, P., Roeder, M., 2013. Temperature of internallycooled diamond-coated tools for dry-cutting titanium. International Journal of Machine Tools and Manufacture 75, 27-35.

Movahhedy, M.R., Altintas, Y., Gadala, M.S., 2002. Numerical analysis of metal cutting with chamfered and blunt tools. Journal of Manufacturing Science and Engineering-Transactions of the Asme 124, 178-188.

Movahhedy, M.R., Gadala, M.S., Altintas, Y., 2000. Simulation Of Chip Formation In Orthogonal Metal Cutting Process: An Ale Finite Element Approach. Mach. Sci. Technol. 4, 15-42.

MSC Software, 2013. MSC. MARC Manual, In: MSC Software Corporation (Ed.).

Naumann, U., 2012. Combinatorial Scientific Computing. Chapman \& Hall.

Ortiz, M., Quigley Iv, J.J., 1991. Adaptive mesh refinement in strain localization problems. Computer Methods in Applied Mechanics and Engineering 90, 781-804.

Østerby, O., Zlatev, Z., 1983. Direct methods for sparse matrices. Springer.

Perić, D., Hochard, C., Dutko, M., Owen, D.R.J., 1996. Transfer operators for evolving meshes in small strain elasto-placticity. Computer Methods in Applied Mechanics and Engineering 137, 331-344.

Rao, S.S., 2011. <<The〉> Finite Element Method in Engineering. Elsevier.

Samet, H., 1990. <<The〉> design and analysis of spatial data structures. Addison-Wesley.

Sauvage, X., Le Breton, J.M., Guillet, A., Meyer, A., Teillet, J., 2003. Phase transformations in surface layers of machined steels investigated by X-ray diffraction and Mössbauer spectrometry. Materials Science and Engineering: A 362, 181-186. 
Schermann, T., Marsolek, J., Schmidt, C., Fleischer, J., 2006. Aspects of the Simulation of a Cutting Process with ABAQUS/Explicit Including the Interaction between the Cutting Process and the Dynamic Behaviour of the Machine Tool, Proceedings of the 9th CIRP International Workshop on Modeling of Machining Operations, Bled, Slovenia, pp. 163-170.

Skorupski, R., Smaga, M., Eifler, D., Mayer, P., Aurich, J.C., 2013. Phase Transformation as a Result of Mechanical Loading and Turning of Metastable Austenitic Steels, TMS2013 Supplemental Proceedings. John Wiley \& Sons, Inc., pp. 877-884.

Tezuka, A., 1992. Adaptive remeshing process with quadrangular finite elements. Advances in engineering software, 185-201.

Umbrello, D., Filice, L., Rizzuti, S., Micari, E., Settineri, L., 2007. On the effectiveness of finite element simulation of orthogonal cutting with particular reference to temperature prediction. Journal of Materials Processing Technology 189, 284-291.

Umbrello, D., Rizzuti, S., Outeiro, J.C., Shivpuri, R., M'Saoubi, R., 2008. Hardness-based flow stress for numerical simulation of hard machining AISI H13 tool steel. Journal of Materials Processing Technology 199, 64-73.

Wyen, C.F., Wegener, K., 2010. Influence of cutting edge radius on cutting forces in machining titanium. CIRP Annals - Manufacturing Technology 59, 93-96. 
Fig. 1: Position of the brazed parts.

Fig. 2: Cubo-octahedral diamond: (a) SEM image. (b) 3D model of the diamond after measurement with focus variation light microscope of Alicona ${ }^{\circledR}$ and post processing with Geomagic Studio ${ }^{\circledR}$.

Fig. 3: Grain engagement orientation; (a): SEM micrograph of rake-face identified with (111) Miller index, (b): 3D optical microscope image of the engagement edge indicated by arrows. The picture is made by Alicona-InfiniteFocus ${ }^{\mathrm{TM}} \mathrm{G} 4$ and with $5 \mathrm{x}$ magnification lens.

Fig.4: Experimental setup of single diamond machining test. Direction of cutting velocity is shown by $\mathrm{V}_{\mathrm{C}}$.

Fig. 5: The flowchart of coupled thermomechanical analysis from (MSC.Software, 2013); the "est" in the chart is the abbreviation of "estimated". Calculation of all the state variables such as stress field and damage field are not mentioned in the flowchart. The stress field is calculated after calculation of the displacement. Damage field is also updated in each increment.

Fig. 6: Overview of the thermal boundary conditions.

Fig. 7: Numerical and experimental cutting forces, $F_{x}$, passive force, $F_{y}$, and normal force, $F_{z}$, for cutting speed of $0.8 \mathrm{~m} / \mathrm{s}$ and $30 \mu \mathrm{m}$ depth of cut. The coordinate system is shown in Fig. 8 .

Fig. 8: (a) IR-thermography of the machining process at a cutting speed of $0.8 \mathrm{~m} / \mathrm{s}$ and $30 \mu \mathrm{m}$ depth of cut; the surface of the diamond is defined with lines. (b) 3D simulated temperature; a cutting edge radius of $7 \mu \mathrm{m}$ is considered based on (Akbari et al., 2015). This image is selected to show that the simulated chip separates from the diamond. The highest temperature inside the cutting zone can be simulated and cannot be detected by IR-thermography.

Fig. 9: The simulations results show the influence of two different cutting edge radii of 0 and $20 \mu \mathrm{m}$ for cutting speed of $0.8 \mathrm{~m} / \mathrm{s}$ and $30 \mu \mathrm{m}$ depth of cut. (a) shows the temperature field when machining with $0 \mu \mathrm{m}$ cutting edge and flash temperature of $754 \mathrm{~K}$ and (b) with $20 \mu \mathrm{m}$ cutting edge and flash temperature of $806 \mathrm{~K}$ for the same simulation time step. Influence of cutting edge radii of $0 \mu \mathrm{m}$ and $20 \mu \mathrm{m}$ on cutting forces is shown in (c).

Fig. 10: Field of damage halfway into the 3D workpiece which is sliced into planes: (a) Machining with $0 \mu \mathrm{m}$ cutting edge radius and (b) Machining with $20 \mu \mathrm{m}$ cutting edge radius. The distance between each of the five sliced planes is $80 \mu \mathrm{m}$. Damage field in machining with $20 \mu \mathrm{m}$ cutting edge radius is around $15 \mu \mathrm{m}$ deeper than machining with $0 \mu \mathrm{m}$ cutting edge radius.

Table 1: Johnson-Cook parameters for Ti-6Al-4V which represent the physics of single diamond machining test.

Table 2: Johnson-Cook damage parameters for Ti-6Al-4V. 